\title{
Biology of Aenasius arizonensis Hayat (Hymenoptera: Encyrtidae) a Nymphal Adult Parasitoid against Cotton Mealybug, Phenacoccus solenopsis Tinsley (Hemiptera: Pseudococcidae)
}

\author{
P. Prithvi* and B. Patro
}

Department of Entomology, College of Agriculture, Orissa University of Agriculture and Technology, Bhubaneswar-751003, India

*Corresponding author

\section{A B S T R A C T}

\section{Keywords}

Phenacoccus solenopsis,

Aenasius arizonensis,

Parasitoid, Biology,

Morphology,

Morphometry

Article Info

Accepted:

24 September 2018

Available Online:

10 October 2018
The study on biology of nymphal adult parasitoid Aenasius arizonensis Hayat on cotton mealybug, Phenacoccus solenopsis Tinsley was conducted under laboratory conditions during February to April, 2016. Preliminary survey on host plants of $P$. solenopsis was conducted along with its natural enemies and A. arizonensis was found to be a commonly occurring natural enemy along with Cryptolaemus montrouzieri. The parasitoids were collected and reared on cotton mealybug for one generation, then allowed to mate. The parasitized mummies of mealybugs were taken separately for emergence of parasitoid and fed on $50 \%$ honey solution. The studies showed that the developmental period of parasitoid till formation of pupa was 10.31 days, pupal stage was 8.60 days. The longevity of adult female wasp was 70.20 days and male wasp was 53.30 days. The total average duration of life cycle was 89.10 days.

\section{Introduction}

Phenococcus solenopsis was found seriously infesting cotton plants during 2005 in the Punjab and Sindh regions of Pakistan (Arif $e t$ al., 2007). Then, it had spread to a large number of cotton growing districts in India and by 2006. Biological control practices have been developed in recent years with the introduction promising parasitoid Aenasius arizonensis (Hayat, 2009), predators like Cryptolaemus montrouzieri, Cheilomenes sexmaculatus, Brumoides suturalis (Sattar et al., 2007; Suroshe et al., 2013)and entomopathogenic fungi like Lecanicillium lecani, Metarrhizium anisopliae, Beauvaria bassiana (Nagrare et al., 2011). In India, the endoparasitoid, Aenasius sp., was reported to attack $P$. solenopsis on different host plants such as cotton, okra, Parthenium hysterophorus, Achyranthes asper etc. (Sharma, 2007; Tanwar et al., 2008). The parasitoid was first identified as Aenasius arizonensis Hayat (Hymenoptera: Chalcidoidea: Encyrtidae) by Insect Identification Service, Division of Entomology, IARI, New Delhi (Hayat, 2009). Promuscidea unfasciativentris Girault (Hymenoptera: Chalcidoidea: Aphelinidae) was identified as another parasitoid (Tanwar $e t$ 
al., 2011), which was earlier identified as hyperparasitoid on $A$. arizonensis (Hayat, 1998).

Fand and Suroshe (2015) mentioned that $A$. arizonensis was effective in controlling the population of $P$. solenopsis upto $30-60 \%$ apart from 28 other species of natural enemies which include predators and parasitoids. This parasitoid was reported from USA, India, Pakistan, China and Iran (Girault, 1915; Hayat, 2009; Bodlah et al., 2010; Chen HuaYan, et al., 2010 and Fallahzadeh et al., 2014). A recent report of the parasitization of the $P$. solenopsis by $A$. arizonensis was also reported on different host plants at Giza region in Egypt (Angel et al., 2017).

The mean duration of development of $A$. arizonensis from egg laying to pupation was 8.85 days and pupation to adult emergence took 7.35 days in males and 7.00 in females. The mean total duration of development of $A$. arizonensis from egg laying to adult emergence was 16.10 days (range 14-18 days). The adult females survived for 70. 95 days and males survived for 49.0 days when fed on $50 \%$ honey (Poorani et al., 2009).

The developmental period of the parasitoid from $1^{\text {st }}$ day of parasitization till emergence of adult wasp from mummies was recorded 12 17 days. Single parasitoid adult was emerged from each mummy of the host, giving evidence that female of parasitoid lay single egg in the host. Male wasp died within $7-10$ days whereas female survived for $15-32$ days. Female parasitoid parasitizes 30 - 165 mealybugs in its whole life (Abdin et al., 2012).

The morphometrical observations recorded by Sangle et al., (2013) were as follows. The mean length and width of the pupa were 3.48 $\pm 0.01 \mathrm{~mm}$ and $1.85 \pm 0.02 \mathrm{~mm}$ respectively. The mean length and width of the adult female were $1.83 \pm 0.03 \mathrm{~mm}$ and $0.80 \pm 0.01 \mathrm{~mm}$ respectively. The mean length and width of the adult male were $1.04 \pm 0.04 \mathrm{~mm}$ and 0.38 $\pm 0.01 \mathrm{~mm}$ respectively.

\section{Materials and Methods}

The host $P$. solenopsis was collected from infested fields and reared in laboratory on potato sprouts, to maintain culture. The parasitoids were collected from $P$. solenopsis infested field twigs of Hibiscus rosa-sinensis were allowed to rear on $P$. solenopsis for one generation. The parasitized mealybug mummies were collected and kept individually for emergence of parasitoids. Upon emergence, the parasitoids were allowed to mate and parasitize the mealybugs of 2 nd instar and above. The parasitized mealybugs were kept separately in glass for observation. Observations on time taken from egg laying to pupation, pupation to adult emergence and adult longevity on 50\% honey were recorded. The time taken from exposure to adult emergence was considered as the total duration of development. The above said procedure was followed as suggested by Poorani et al., (2009). The different visual stages of parasitoids were observed for morphometrical readings for color and shape using stereoscopic microscope.

\section{Results and Discussion}

The observation on life stages of parasitoid revealed that the time taken from parasitization to pupal stage ranged from 8 12 days with a mean of $10.31 \pm 1.56$ days. The swelling of the host was observed after 3 - 4 days of parasitization and they are called mummies or mummified insects. The mummies were leathery brown structures. The parasitoid pupa inside the body of the mummies was hard, shiny and brown. The Duration of pupa ranged from 7 to 10 days with a mean of $8.60 \pm 1.07$ days and the length 
of pupa ranged from 2.70 to $3.70 \mathrm{~mm}$ with a mean of $3.10 \pm 0.37 \mathrm{~mm}$ whereas width ranged from 1.6 to $2.1 \mathrm{~mm}$ with a mean of $1.80 \pm 0.20 \mathrm{~mm}$ and only one parasitoid was emerged from one mummified insect.

The total duration from egg to adult emergence ranged from 15 to 20 days with a mean of $18.91 \pm 1.90$ days. The longevity of adult females and males when reared on $50 \%$ honey ranged from 49 to 84 (Av. $70.20 \pm$ 12.39) and $35-66$ (Av. $53.30 \pm 9.23$ ) days, respectively. The length and width were 1.60 2.60 (Av. $2.06 \pm 0.03 \mathrm{~mm}$ ) and $0.70-0.95$ (Av. $0.80 \pm 0.01 \mathrm{~mm}$ ) for female and 0.90 1.60 (Av. $1.26 \pm 0.02 \mathrm{~mm}$ ) and $0.35-0.60$ (Av. $0.45 \pm 0.01 \mathrm{~mm}$ ) for male. The total duration from egg laying to the adult mortality ranged from 64 to 105 days with a mean of $89.10 \pm 13.90$ days (Table 1 and 2). The body of the parasitoid is shiny black coloured with punctured like appearance of pronotum and the abdomen is dark brown. The male was smaller in size than the female. The wings were translucent, but in male wing length was longer than the body length and reverse was the case with the female. The female parasitoids were easily distinguished due to presence of pointed and long ovipositor at the end of the abdomen (Fig. 1-4). Poorani et al., (2009) reported that the mean duration of development from egg laying to pupation was 8.85 days and pupation to adult emergence was 7.35 days in males and 7.00 in females. The mean total duration of development from egg laying to adult emergence was 16.10 days. The adult females survived for 70.95 days and males survived for 49.0 days when fed on $50 \%$ honey, which supported the present findings.

Table.1 Duration of life stages of Aenasius arizonensis on Phenacoccus solenopsis in laboratory under ambient conditions

\begin{tabular}{|l|c|c|}
\hline \multicolumn{1}{|c|}{ Life stage } & \multicolumn{2}{|c|}{ Duration (days) } \\
\hline Egg + Larva & Range & Mean \pm SD \\
\hline Pupa & $8-12$ & $10.310 \pm 1.567$ \\
\hline Total & $7-10$ & $8.600 \pm 1.074$ \\
\hline Female & $15-21$ & $18.910 \pm 1.969$ \\
\hline Male & $49-84$ & $70.200 \pm 12.398$ \\
\hline
\end{tabular}

Table.2 Morphometry of A. arizonensis

\begin{tabular}{l|c|c|}
\multicolumn{1}{|c|}{ Life stage } & \multicolumn{2}{|c|}{ Morphometry $(\mathrm{mm})$} \\
\hline Pupa & Range & Mean \pm SD \\
\hline $\begin{array}{l}\text { Length } \\
\text { Width }\end{array}$ & $2.7-3.7$ & $3.10 \pm 0.37$ \\
\hline $\begin{array}{l}\text { Adult Female } \\
\text { Length }\end{array}$ & $1.6-2.1$ & $1.80 \pm 0.20$ \\
\hline $\begin{array}{l}\text { Width } \\
\text { Adult Male }\end{array}$ & $1.60-2.6$ & $2.06 \pm 0.03$ \\
Length & $0.70-0.95$ & $0.80 \pm 0.01$ \\
\hline Width & $0.90-1.60$ & $1.26 \pm 0.02$ \\
\hline
\end{tabular}


Fig.1 Aenasius arizonensis parasitized mummies of $P$. solenopsis on China rose

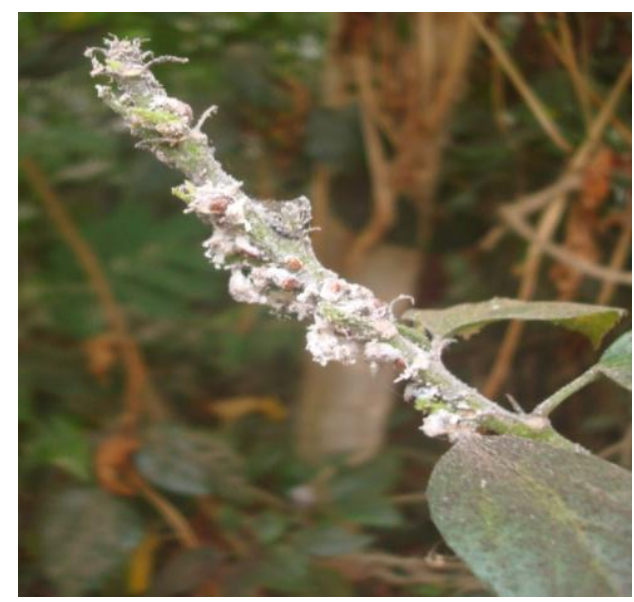

Fig.2 Pupae of A. arizonensis

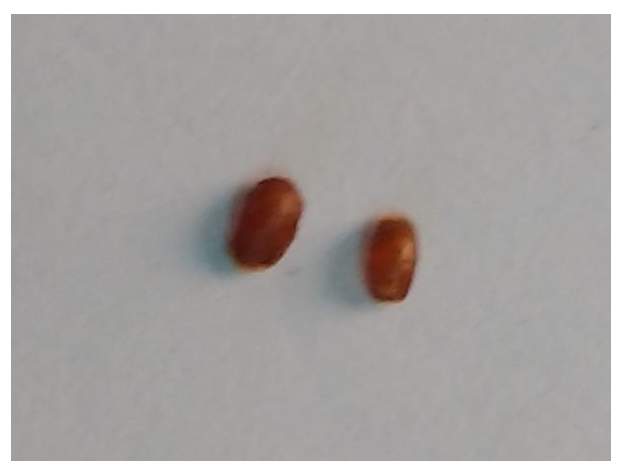

Fig.3 Adult male of A. arizonensis

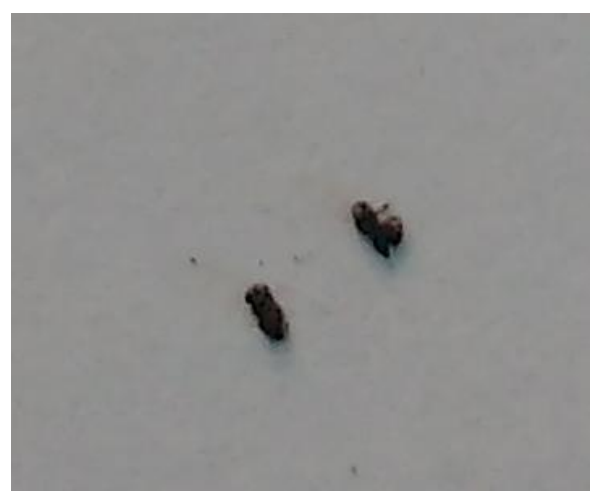

Abdin et al., (2012) reported the total development period from parasitization to emergence of adult ranged from 12 to 17 days. The longevity of adult male and female ranged from 7 to 10 days and 15 to 32 days respectively, which varied with present study.
Fig.4 Adult female of $A$. arizonensis

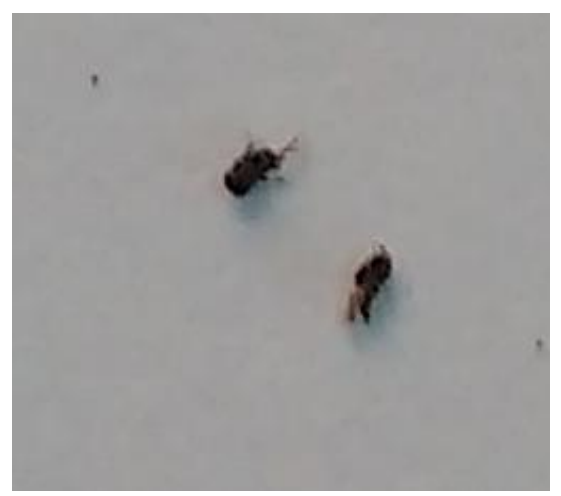

The findings of the present study corroborates to the findings of Sangle et al., (2013). The biology studies of the current research varied with the findings of Aga et al., (2016), who mentioned the maximum longevity of the adult female and male to be 34 and 24 days 
respectively. The morphometrical observations were in coincidence with the present findings.

\section{Acknowledgments}

The authors are grateful and whole heartedly thank Head of the Department of Entomology, O.U.A.T., Bhubaneswar, Odisha for his continuous support and timely response whenever in need. The authors are also express gratitude to the staff of the Division of Biological Control.

\section{References}

Abdin, Z., Arif, M. J., Gogi, M. D., Arshad, M., Hussain, F., Abbas, S. K., Shaina, H. and Manzoor, A. 2012. Biological characteristics and host stage preference of mealybug parasitoid Aenasius bambewalai Hayat (Hymenoptera: Encyrtidae). Pakistan Entomologist 34(1): $47-50$

Aga, T. M., Tambe, V. J., Nagrare, V. S. and Naikwadi, B. 2016. Parasitoid, Aenasius arizonensis (Girault) (Hymenoptera: Encyrtidae): Its biology, morphometrics, host stage preference and use in biological control. Journal of Biological Control 30(2): 91-98

Angel, R. A., Kamal T. A. and John N. 2017. First Record of Aenasius arizonensis (Hymenoptera: Encyrtidae) as a solitary, Endoparasitoid of Cotton Mealybug, Phenacoccus solenopsis Tinsley (Hemiptera: Pseudococcidae) Infesting Different Host Plants at Giza Region in Egypt. Egyptian Academic Journal of Biological Sciences 10(7): 127-134

Arif, M. J., Abbas, G. and Saeed, S. 2007. Cotton in danger. DAWN, March., Pakistan: Pakistan Herald Publication.

Bodlah, I., Ahmad, M., Nasir, F. and Naeem, M. 2010. Record of Aenasius bambawalei Hayat, (Hymenoptera:

Encyrtidae), a parasitoid of Phenacoccus solenopsis Sternorrhyncha: Pseudococcidae) from Punjab, Pakistan. Pakistan Journal of Zoology 42(5): 533-536.

Chen Hua- Yan, Cao Run-Xin and Xu Zai-Fu. 2010. First record on Aenasius bambawalei Hayat (Hymenoptera: Encyrtidae) a parasitoid of the mealybug, Phenacoccus solenopsis tinsley (Hemiptera: Pseudococcidae). China Journal of Environmental Entomology 32(2): 280-282.

Fallahzadeh, M., Japoshvili, G., Abdimaleki, R. and Saghaei, N. 2014. New records of Tetracneminae (Hymenoptera, Chalcidoidea, Encyrtidae) From Iran. Turkish Journal of Zoology 38: 515518.

Fand, B. and Suroshe, S.S. 2015. The invasive mealybug Phenacoccus solenopsis Tinsley, a threat to tropical and subtropical agricultural and horticultural production systems - a review. Crop protection 69: 34-43.

Girault, A.A. 1915. New Chalcidoid Hymenoptera. Annals of Entomological Society of America 8: 279-284.

Hayat, M. 2009. Description of a new species of Aenasius Walker (Hymenoptera: Encyrtidae), parasitoid of the mealybug, Phenacoccus solenopsis Tinsley (Homoptera: Pseudococcidae) in India. Biosystematica 3: 21-26

Hayat, M.1998. Aphelinidae of India (Hymenoptera: Chalcidoidea): A taxonomic revision. Memoirs on Entomology International pp. 416

Nagrare, V. S., Kranthi, S., Kumar, R., DharaJothi, B., Amutha, M., Deshmukh, A. J., Bisane, K. D. and Kranthi, K. R. 2011. Compendium of Cotton Mealybugs. Central Institute for Cotton Research, Nagpur, India. 42 pp 
Poorani, J., Rajeshwari, S. K. and Gupta, A. 2009. Notes on diagnosis and biology of Aenasius bambawalei Hayat (Hymenoptera: Encyrtidae), a parasitoid of the invasive mealybug, Phenacoccus solenopsis Tinsley (Hemiptera: Sternorrhyncha: Pseudococcidae). Journal of Biological Control 23(4): 463-466

Sangle, P. M., Korat, D. M., Patel, B. H. 2013. A note on morphometry and post larval life stages of Aenasius bambawalei Hayat. Karnataka Journal of Agricultural Sciences 26 (1): (152154)

Sattar, M., Hamed, M. and Nadeem, S. 2007. Predatory potential of Chrysoperla carnea (Stephens) (Neuroptera: Chrysopidae) against cotton mealybug. Pakistan Entomologist 29(2): 103 - 106

Sharma, S. S. 2007. Aenasius sp. novel effective parasitoid of mealynug
(Phenacoccus solenopsis) on okra. Haryana Journal of Horticultural Sciences 36(3): 412

Suroshe, S. S., Gautam, R. D. and Fand, B. B. 2013. Natural enemy complex associated with the mealybug, Phenacoccus solenopsis Tinsley (Hemiptera: Pseudococcidae) infesting different host plants in India. Journal of Biological Control 27: 204 - 210.

Tanwar, R. K., Jeyakumar, P., Singh, A., Jafri, A. A. and Bambawale, O. M. 2011. Survey for cotton mealybug, Phenacoccus solenopsis (Tinsley) and its natural enemies. Journal of Environmental Biology 32: 381-384

Tanwar, R., Bhamare, V., Ramamurthy, V., Hayat, M., Jeyakumar, P., Singh, A. and Bambawale, O. 2008. Record of new parasitoid on mealybug, Phenacoccus solenopsis. Indian Journal of Entomology 70(4): 404-405.

\section{How to cite this article:}

Prithvi, P. and Patro, B. 2018. Biology of Aenasius arizonensis Hayat (Hymenoptera: Encyrtidae) a Nymphal Adult Parasitoid against Cotton Mealybug, Phenacoccus solenopsis Tinsley (Hemiptera: Pseudococcidae). Int.J.Curr.Microbiol.App.Sci. 7(10): 3423-3428. doi: https://doi.org/10.20546/ijcmas.2018.710.397 